\title{
DEVELOPING A REGIONAL SOLUTION TO DIGITAL TRANSFORMATION OF HEALTH CARE SERVICES: COLLABORATION, LEADERSHIP, AND TECHNOLOGICAL EXPERTISE
}

\author{
Hilde G. Corneliussen \\ Western Norway Research Institute \\ Box 163, 6851 Sogndal, Norway
}

\begin{abstract}
This paper analyses a regional solution to digital transformation of health care services in Norway during the period 2014 to 2020. Facing the national health authorities' requirements for implementing welfare technology in public health care services, this rural region with its many small and medium-sized municipalities developed a unique framework for supporting this task across the small units. First, collaboration between organizations representing a wide set of competences, roles, and positions in the region and locally; second, a regional center responsible for developing health care services that - unlike other similar centers in Norway, took on a role to lead this work; and third, a regional emergency central originally developed for fire services taking on the role as the technical expert in the region. The analysis is based on documentation, project reports and interviews with participants from the project. While national guidelines for implementation of welfare technology have been important for motivating this work, many challenges were left for municipalities to solve, in particular the question pursued here: how should local and regional traditions be transformed to integrate technology in a sector and among professional groups that traditionally have not been associated with technology? The findings show that the regional model for collaboration supported the municipalities' health care services in this task by building on a regional model for cross-sectoral collaboration as well as regional trusted networks and channels of communication in unique ways in a national context.
\end{abstract}

\section{KEYWORDS}

Welfare Technology, Regional Development, Rural Regions, Collaborative Network

\section{INTRODUCTION}

Since the early 2010s, new digital technology, often referred to as care technology or welfare technology in Norway, has become increasingly important for the public health care services (NOU, 2011:11). This digital transformation has been motivated by an expected increase in the number of persons in need of care services, without a corresponding increase in health care personnel. In Norway, as in other western countries, this has created a need for delivering health care services in new ways (Moe et al., 2019). Welfare technology has been launched as one of the solutions that will enable the health care sector to maintain the quality of the services facing the increasing gap between need and personnel (Frennert \& Baudin, 2019; Helsedirektoratet, 2012; Karlsen et al., 2019). The direction of this effort in Norway has been pointed out through national guidelines and recommendations, in particular emphasizing technology that can support delivery of health and care services in patients' homes, to increase safety and security (Melting, 2017; Melting \& Frantzen, 2015). One factor that was not clearly defined in the early national guidelines was: how should local and regional traditions be transformed to integrate technology in a sector and among professional groups that traditionally have not been associated with technology?

This paper analyses how implementation of welfare technology in a geographically vast but sparsely populated rural region in the western part of Norway started from scratch in 2014 and has spread to all municipalities in 2020. The region is the former county Sogn \& Fjordane with 26 municipalities with between 800 and 13.000 inhabitants. This region, rural and remote from the national capital, does not in all aspects 
reflect the larger and more densely populated regions that were among the main test areas for the early national advices; the needs in the region do not mirror a city, and many of the small and medium-sized municipalities did not have available personnel with the necessary technological expertise or the innovation and project competence to support the introduction of new technology in health care services (Corneliussen \& Hove, 2017). Furthermore, the national guidelines were experienced as vague and difficult for the smaller municipalities, among other things because some of the recommended technologies were not available in small-scale versions (Hove \& Corneliussen, 2017). On the other side, certain regional factors in Sogn \& Fjordane contributed to the task of implementing welfare technology. This paper discusses three factors found to support the digital transformation in this region: first, collaboration between organizations representing a wide set of competences, roles, and positions in the region and locally; second, a regional center responsible for developing health care services that - unlike other similar centers in Norway, took on a role to lead this work; and third, a regional emergency central originally developed for fire services taking on the role as the technical expert in the region. This has developed a framework that has given the relevant institutions knowledge and ability not only to work with the ongoing digital transformation in health care, but also to react and move quickly when situations, like the recent Corona crisis, requires an immediate restructuring of health care services.

The analysis is based on documentation from a 6 year project for implementation of welfare technology in the region Sogn \& Fjordane in Norway, including project reports, project notes and data material collected during the project period (Corneliussen, 2014b, 2015; Corneliussen et al., 2016; Hove \& Corneliussen, 2017; Hove \& Corneliussen, 2018). The data material includes interviews with administrative and health care personnel from municipalities' health care services, two surveys mapping the municipalities' use of and self-reporting knowledge about welfare technology, the researcher's notes from observations in the municipalities' working groups for implementation of welfare technology as well as from project meetings in the IT-forum working group described below.

Below we will explore each of the three success factors before we discuss how this has strengthened the region's ability to deal with challenging situations and crisis.

\section{DEVELOPING REGIONAL KNOWLEDGE}

Norway has a public health care system with the main responsibility for all nursing and health care services. Public health care represents one of the largest costs for municipalities that are responsible for providing such services, to, among others, a growing elderly population. While new digital technology includes solutions that can improve the quality of health care services, an equally important motivation for the current implementation of welfare technology is to meet the growing costs in the health care sector (Meld. St. 15 (2017 -2018); Melting, 2017; Melting \& Frantzen, 2015). The goal is to use digital technology when it can benefit users as well as services. The national guidelines state that new technology can and should be a substitute for physical visits in user's home when selected on the basis of individual mapping of users' needs (Melting \& Frantzen, 2015). Thus, in rural regions with long distances of travelling between users, welfare technology can have a major impact on the costs of the growing need for health care services. One such example that makes a difference for both users and services in this region, is digital medication dispensers that can remind users to take their medicine at the correct time. This can improve the quality of medication as well as reducing the number of home visits, or alternatively, providing more flexibility in the exact timing of home visits, for health care personnel (Corneliussen et al., 2016).

Profit realization and cost benefit analysis are keywords for monitoring and securing that new technology is in fact able to make savings. However, it takes time, effort, and money to figure out how to reach such goals from the first introduction of new technology, reorganizing the services, and to identify the actual benefit of new technology (Smaradottir et al., 2019). Furthermore, it requires a diversity of competences, from being familiar with technology, knowledge about innovation and restructuring processes, insight and knowledge about legal, ethical, and other practical questions and challenges that need to be at the forefront of such a digital transition. That means, this process requires competences that have not traditionally been a part of the health care personnel's education (Cajander et al., 2020). Facing these challenges, this particular region developed a solution that is different from other regions in Norway, by building a network inviting all the 26 municipalities together with a wide set of actors with different types of knowledge and competence with relevance for this work. The main building blocks that make this network special, are the way of organizing the collaborative network, the leadership of this work, and the technological expertise in the network. 


\subsection{Gathering Competence in a Collaborative Network}

While efforts to introduce digital technology for support in health care services has a longer history, it was particularly from 2013 that the municipalities in Sogn \& Fjordane started to engage in this work. In spring 2014 a collaborative initiative managed to secure funding for one year, and since then, this project has received economic support from the County Governor for the project "Welfare technology in the municipalities of Sogn \& Fjordane", while the municipalities themselves contributed $50 \%$ of the funding. The group behind this was organized through a collaborative network with long roots in the region: IT-forum Sogn \& Fjordane. This is a network established in the 1990s with the aim of supporting regional actors, public as well as private, to build infrastructure for and take up efficient use of digital technologies (Larsen \& Corneliussen, 2016). This network has a unique way of organizing cross-sectoral collaboration that has been labelled the "Sogn \& Fjordane model". The features of this model are that all relevant actors are invited, together they define the challenge and decide how to solve it, and in collaboration they work for enacting and implementing solutions (Corneliussen \& Larsen, 2018). A working group with the name "welfare technology" was established under this network, and the participating partners of this group included municipalities with representatives from health care services, administration, and IT departments; Center for development of institutional and home-care services (USHT), a public organization responsible for fitting technical health care equipment for users, representatives from the county governor, the county and a high school, a regional university college and a research institute. In later years, this group has also included specialist healthcare services, a company developing exhibitions for health care technology, and an emergency central in the county.

One of the unique qualities of this network is that it is entirely voluntary to participate and the organization is quite loose. Although it is open for all relevant institutions and organizations, it is not a democratic group in the sense of representing "everybody", but rather based on "people who are willing to contribute" in the network and for the task at hand. While this can be challenging because it makes both authority and responsibility in the group vague, it also means that this collaborative network is not challenging the municipalities' or institutions' own power structures, which often seems to be one of the main challenges to overcome in such cross-sectoral and cross-institutional collaborations (Corneliussen \& Larsen, 2018). At the same time, this network is recognized and respected in the region, giving it legitimacy and trust that facilitates the process of gathering the actors (Larsen \& Corneliussen, 2016). Furthermore, one of the most valuable aspects of this network is the way it facilitates collaboration between organizations representing a wide set of competences, roles, and positions in the region and locally. This reminds of the bazaar in Raymond's analysis of the cathedral versus the bazaar (Raymond, 1999). While the cathedral represents a top-down structuring of a highly hierarchic organization, the bazaar represents a bottom-up organization were each representative brings her own specialty and expert knowledge. Each member of the group brought a particular background, experience, and knowledge that together made this group a creative and dynamic arena for developing competence within the digital transformation of health care services, which is a challenge that requires expert knowledge from many fields (Corneliussen \& Larsen, 2018). This also meant that each member of the group could benefit from the network and bring valuable insights back to their own organization (ibid.).

The collaborative project described here has given legitimacy to the municipalities' efforts to implement welfare technology, a task that met many critical and skeptical reactions at first, from a fear for technology to replace human contact (Corneliussen et al., 2016), to a reluctancy towards "fumbling with something technical that we can't make work" instead of doing it "the old way" without technology support (Corneliussen \& Hove, 2017). This group has strengthened the otherwise small actors, municipalities, and institutions, and eventually the group effort succeeded in securing funding from the National Welfare Technology Program for all municipalities in 2019 - an accomplishment that would not have been possible without the group effort. Thus, currently all municipalities in this region have united to work towards the health authorities' goal, which is to make welfare technology an integrated part of public health care services by the end of year 2020 (Helse- og omsorgsdepartementet, 2015).

\subsection{A Regional Center for Development of Health Care Services}

One of the success factors for this work was that the regional center, USHT, took on a role to lead this work. USHT has a mandate from the national health authorities that includes the responsibility for developing knowledge and competence among health care service institutions in the region. There are 21 similar centers 
across Norway with a responsibility for different regions of the country. The center in this particular region chose a different strategy than the other centers through this network, by taking a leading position in the work to encourage and help the municipalities implementing welfare technology. This gave a major advantage to the network group, as USHT was already recognized by health care units and institutions as well as the municipalities' administrative leaders across the county. USHT also has a wide network and is an arena for communication of knowledge and expertise in health care services in this region. The reason for USHT joining this group and taking on the role as a leader was in the beginning coincidental. However, recognizing that the IT-forum working group was a way of mobilizing institutions and actors that were not already within the center's own network made this collaborative group valuable also for USHT. Furthermore, it was an opportunity for USHT to see the implementing welfare technology in relation to other development processes in which the center already was guiding the municipalities. This produced a synergy in this work, strengthening the network of people who worked together. It also gave additional input to and motivation for several parallel processes of developing health care services that the municipalities were involved in by establishing recognizable patterns and methodologies for dealing with innovation and organizational change in the field (Helse- og omsorgsdepartementet, 2015).

\subsection{Regional Technical Expertise}

Facing the new requirements for implementing and integrating new technical solutions in health care services involves processes of fitting and developing organizational routines to a new way of providing health care. This project has illustrated that health care workers are used to working under pressure and to react quickly to solve urgent and critical situations, like one of the participants described it (Hove \& Corneliussen, 2017). This gave a lot of momentum in the work once it had started. However, the same processes required a certain level of knowledge about the relevant technological solutions. As Corneliussen and Dyb have shown, the health authorities launched a discourse about welfare technology claiming that it had mostly to do with humans and organization of health care services, promoting the idea that welfare technology was something that could be implemented mainly with a focus on humans and organization (Corneliussen \& Dyb, 2017). While this strategy can be seen as one way of motivating a non-technical health care profession to engage with a technology implementation process, this also undermined the need for technical competence in a way that made many health care leaders struggle with this new technology. This was particularly challenging for some of the smaller municipalities that did not have their own IT experts, but rather relied on an external organization of IT support shared between several municipalities (Corneliussen et al., 2016). One of the early participants illustrates some of the challenges created by this discourse: with a background in nursing and at the time administrative head of a municipality's health care services, this new process forced her to do what an IT person should have done, she says, and to attend the meetings that required IT competence, and to enter into negotiation with technology producers (Corneliussen et al., 2016).

This tendency of health care personnel being responsible for developing the services with new technology that they had weak knowledge about, sometimes even technology that had not been fully developed (Hove \& Corneliussen, 2018), was one of the biggest challenges across the municipalities in the region. While this certainly was a challenge also in other region, it was made additionally complicated by the lack of technology experts in the municipalities' administrations. Also, this challenge found a solution that was specific to this region. An intra-municipality emergency alarm central, originally established for fire services, was already organizing the old type of analogue safety alarms aiming to support, in particular, elderly people to continue living safely in their own home. When these safety alarms gradually where exchanged for new digital alarms, this gave opportunities to connect other types of alarms in the range of more advanced welfare technology. Soon, the emergency central became a hub for knowledge about a wide set of concrete e-health solutions, and it increasingly took on a role of representing the technological expertise that the municipalities did not have themselves. 


\section{DISCUSSION}

Implementation of welfare technology has been a long and cumbersome process for many municipalities across Norway. Health authorities optimistically claimed in 2013 that this process was to be completed by 2018. It has later become clear that it will take longer to make welfare technology a natural and integrated part of the municipalities' health care services. The project described here installed a unique regional solution to this challenge. All the municipalities have certainly put in a lot of effort in this project, and many of them would undoubtedly have managed to do this on their own as well. However, among the participating municipalities, many have claimed that they would not have been able to raise this effort as early as they did without the collaborative network and the project. The many small municipalities in this region cannot pursue this work the same way as larger units in more central and densely populated regions of the country. The IT-forum network, with its long history in the region of promoting the collaborative "Sogn \& Fjordane-model" inviting a wide set of participants to an organizational loose but powerful working group, is a unique tool for achieving advanced results across the many small units in this rural region (Corneliussen, 2014a). In this project it made all the small and medium-sized municipalities able to work together as one large group, giving them strength that each one of them did not have on their own. The leadership of USHT in this process contributed by legitimating the work through recognized arenas for sharing and developing knowledge about the quality of health care services, and with a wide network of contacts among communities of practice, health care personnel and municipality administrators across the county. The emergency alarm central entered the scene in the first phase of the project with a sorely needed technological expertise that filled a gap that the health authorities' discourse of welfare technology had contributed to by undermining the need for technological competence.

While these three factors, the collaborative network, USHT's leading role, and the technical expertise of the emergency central, have been identified as crucial for supporting and helping the municipalities in this region into actively implementing welfare technology, they were not part of the national advices for this work. Instead, they grew out of the regional tradition, illustrating the innovative power in the "Sogn \& Fjordane-model" of collaborating across units, institutions, and actors that represent different experiences, competences, and responsibilities, and the loose, yet widely trusted way of organizing this collaboration. The innovative work in the region has been communicated back to the national health care authorities and has contributed to a more nuanced understanding of regional and local conditions. Furthermore, the network of collaborative partners, the close contact between relevant institutions, organizations, and companies as well as the knowledge about local and regional conditions has also produced a flexible framework that can act quickly. When Corona made personal face-to-face contact difficult during the spring of 2020, this network was quick to react when a regional bank and a regional bank fund wanted to fund tablets for nursing homes in the region. With USHT in the lead, tablets were soon distributed through this network together with a quick-guide and a demo-video for employees, and user support for implementing video solutions for elderly users to speak with their relatives. ${ }^{1}$

\section{CONCLUSION}

"When I walk down the street, I feel like a superhero", one of the participants of the central hub of this network, IT-forum Sogn \& Fjordane, has said, referring to how the network provides a collaborative strength to the many small units in this rural region (Corneliussen \& Larsen, 2018). The framework for implementation of welfare technology in this region has indeed brought superpowers to the participants, by lifting the general level of knowledge and contributing to a recognizable network of people with knowledge and competence about welfare technology. Furthermore, the project has contributed to motivating the development of internal organization for the work in each of the municipalities. And finally, the achievements in the region have made the project and the relevant regional actors visible on the national arena. While none of the municipalities in this region were included in the initial round of funding from the National welfare technology program, all the

\footnotetext{
1 See https://ushtsognogfjordane.no/koronavirus/velferdsteknologi/oppstart-av-videokommunikasjon-i-kommunar-i-tidligare-sogn-ogfjordane.120298.aspx and https://www.ks.no/fagomrader/helse-og-omsorg/velferdsteknologi3/nasjonalt-velferdsteknologiprogram/flerekommuner-har-anskaffet-videolosning-sammen/
} 
municipalities have been included in this program since 2019, as a result of the collective strength, now recognized as an active and dynamic innovative structure, rather than small units.

Furthermore, during the Corona crisis that turned the entire society upside down overnight in March 2020, the collaborative network and the municipalities' new competences about digital technology was put to the test, documenting that they were able to make quick adjustments and decisions that involve technology. This suggests that the project that initially started because of national requirements for implementing welfare technological solutions to health care services has succeeded through the unique regional framework not only in equipping the municipalities for the task, but has also established a dynamic network of expertise in the region, ready to act during a crisis.

When this project started in 2014, the participants had little knowledge about how to implement technology in health care services, and how to organize it across a rural region with many small units. Although the national advices and, in the later phases of the project, also the economic support from the national health authorities, have been vital for the positive results, so has the regional framework of collaboration under IT-forum Sogn \& Fjordane, the leadership by USHT, and expertise from the emergency central. Different from the national guidelines describing the implementation process in a rather uniform way, this illustrates the necessity of taking regional factors and conditions into consideration to secure successful implementation of welfare technology across units of different sizes and shapes.

\section{ACKNOWLEDGEMENT}

This project was funded by the County Governor of Sogn \& Fjordane. I want to thank all the partners in the project as well as informants participating in surveys and interviews during the six years of this project. A special thank you to Marta Strandos, leader of USHT, who has contributed to developing this analysis.

\section{REFERENCES}

Cajander, Å., Corneliussen, H. G., Myreteg, G., \& Dyb, K., 2020. What Brings Women into eHealth? Women's Career Trajectories in Digital Transformations in Healthcare Proceedings of the 12th International Conference on e-Health.

Corneliussen, H. G., 2014a. A Success Story about a Communication Reform in the County of Sogn \& Fjordane'. In C. E. Moe \& M. Fossum (Eds.), Proceedings from Scandinavian Conference on Health Informatics, August 21-22, 2014, Grimstad, University of Agder, Norway.

Corneliussen, H. G., 2014b. Velferdsteknologi - status i kommunane i Sogn og Fjordane, Vestlandsforsking-rapport nr. $11 / 2014$.

Corneliussen, H. G., 2015. Velferdsteknologi for kommunane i Sogn og Fjordane - Prosjektstatus, Vestlandsforsking-notat nr. $1 / 2015$.

Corneliussen, H. G., \& Dyb, K., 2017. Om teknologien som ikke fikk være teknologi - diskurser om velferdsteknologi. In J. R. Andersen, E. Bjørhusdal, J. G. Nesse, \& T. Årethun (Eds.), Immateriell kapital. Fjordantologien 2017 (165-181): Universitetsforlaget.

Corneliussen, H. G., \& Hove, M. H., 2017. New Technology in Norwegian Municipalities' Health Care Services: Experiences in Small Rural Municipalities. In S. Martinez, A. Budrionis, A. Bygholm, M. Fossum, G. Hartvigsen, M. Hägglund, C. E. Moe, E. Thygesen, V. Vimarlund, \& K. Y. Yigzaw (Eds.), Proceedings from The 15th Scandinavian Conference on Health Informatics 2017 Kristiansand, Norway, August 29-30, 2017 (1-7): Linköping University Electronic Press.

Corneliussen, H. G., \& Larsen, Ø. H., 2018. På jakt etter suksessformelen for samarbeidsnettverket IT-forum Sogn og Fjordane. In D. M. Berge, K. Y. Dale, \& H. Hogset (Eds.), Det regionale i det internasjonale. Fjordantologien 2018 (101-117): Universitetsforlaget.

Corneliussen, H. G., Strandos, M., \& Hove, M. H., 2016. Evaluering av pilotar i prosjektet velferdsteknologi i kommunane i Sogn og Fjordane: eit prosjekt for å etablere lokal erfaring med velferdsteknologi: Vestlandsforsking-rapport 8 / 2016.

Frennert, S., \& Baudin, K., 2019. The concept of welfare technology in Swedish municipal eldercare. Disability and Rehabilitation, 1-8. doi:10.1080/09638288.2019.1661035

Helse- og omsorgsdepartementet, 2015. Omsorg 2020. Regjeringens plan for omsorgsfeltet 2015-2020.

Helsedirektoratet, 2012. Velferdsteknologi. Fagrapport om implementering av velferdsteknologi i de kommunale helse- og omsorgstjenestene 2013-2030. 
Hove, M. H., \& Corneliussen, H. G., 2017. Velferdsteknologi i kommunar i Sogn og Fjordane - Fase 3, avsluttande rapport: Vestlandsforsking-rapport 11/2017.

Hove, M. H., \& Corneliussen, H. G., 2018. Velferdsteknologi for kommunane i Sogn og Fjordane - spreiing og implementering: Vestlandsforsking-notat 3/2018.

Karlsen, C., Moe, C. E., Haraldstad, K., \& Thygesen, E., 2019. Caring by telecare? A hermeneutic study of experiences among older adults and their family caregivers. Journal of clinical nursing, 28(7-8), 1300-1313.

Larsen, Ø. H., \& Corneliussen, H. G., 2016. An Informal Multi-Stakeholder Network as a Collaborative Strategy Tool in e-Health. Proceedings from IADIS, eHealth conference 2016.

Meld. St. 15 (2017 -2018), Leve hele livet - En kvalitetsreform for eldre: Meld. St. 15 (2017 -2018) Melding til Stortinget.

Melting, J. B., 2017. Andre gevinstrealiseringsrapport med anbefalinger: Nasjonalt velferdsteknologiprogram, Helsedirektoratet.

Melting, J. B., \& Frantzen, L., 2015. Første gevinstrealiseringsrapport med anbefalinger: Nasjonalt velferdsteknologiprogram, Helsedirektoratet.

Moe, C. E., Thygesen, E., \& Aanestad, M. (2019). Dilemmas in Scaling up Telemedical Services. Paper presented at the SHI 2019. Proceedings of the 17th Scandinavian Conference on Health Informatics, November 12-13, 2019, Oslo, Norway.

NOU, 2011:11. Innovasjon i omsorg.

Raymond, E., 1999. The Cathedral and the Bazaar. Philosophy \& Technology, 12(3), 23.

Smaradottir, B., Sjaavaag, S., Ås, I.-A. N., Bakke, B., Alfsen, L., Tangene, W., \& Fensli, R. (2019). Why is it so Hard to Integrate Telemedicine as a Part of Municipal Health Care Services? Experiences from a Norwegian Municipality. Paper presented at the SHI 2019. Proceedings of the 17th Scandinavian Conference on Health Informatics, November 12-13, 2019, Oslo, Norway. 